\section{Articulating the aims of science}

Nicholas Maxwell, of the Department of History and Philosophy of Science at University College, London, offers this comment on the current state of the art

MODERN science is, I suggest, seriously harmed by a widespread attempt to make science conform to a wholly inadequate philosophy of science-a philosophy of science which quite grotesquely misrepresents the basic intellectual aims of science.

This indequate philosophy of science may be called 'standard empiricism'. It is carelessly and unthinkingly taken for granted by the scientific establishment today. It is defended by almost all contemporary philosophers of science-from Popper to Kuhn, Lakatos, Hesse and Grünbaum-as constituting a rigorous, rational conception of science, even though elementary arguments show decisively that the view fails miserably to exhibit science as a rational enterprise.

The basic idea of this philosophy of standard empiricism is that the fundamental intellectual aim of science is simply to improve our knowledge of value-neutral factual truth, scientific progress being assessed in terms of how successfully this aim is being realised. $A$ priori knowledge about matters of fact being denied, it is held that in science theories must be assessed, in the end, solely in terms of empirical success.

In fact, of course, science does not seek to improve our knowledge of factual truth as such; rather, quite properly, science seeks to improve our knowledge of important factual truth, truth that we deem to be in some way valuable, significant, interesting, beautiful, useful, from either a cultural or a practical, technological standpoint. Progress in science is assessed in terms of the amount of valuable factual truth that is being discovered: accumulation of trivia, however extensive, does not, and ought not, to be judged to amount to progress.

Once it is acknowledged that a basic intellectual aim of science is to discover valuable truth, it becomes clear that the aims of science must remain permanently and profoundly problematic. What is there to discover that is, in one way or another, valuable or useful? In what direction do really important, exciting future discoveries lie? What ought to be the general priorities of scientific research? What is at present of greatest importance or value, from a human, social standpoint? Important to whom? What kinds of things will we most need to know in fifty or one hundred years' time? These questions are all highly controversial and problematic just because they concern the domain of our ignorance, and difficult issues concerning human needs, aspirations and values.

It is of fundamental importance that we make the best possible choice of aims for science; and it is almost inevitable that we will fail. Here above all, then, we need to proceed intelligently, critically, imaginatively, wisely. If science is to proceed in a truly rigorous and rational fashion it is essential that we articulate, explore and criticise possible and actual aims for science as an integral part of scientific enquiry, providing ourselves with a wealth of critically examined alternatives, so that we may enhance our capacity to choose wisely and well. Quite generally one can say that rigour involves making explicit and so criticisable that which is implicit, influential and problematic. The best aims for science lie in the direction of the overlap between that which is scientifically realisable, and that which is humanly desirable. In order to give ourselves the maximum chances of discovering this problematic region of overlap we need to articulate both that which we conjecture to be scientifically realisable and that which we conjecture to be humanly desirable.

A truly rigorous, rational science would, then, include three kinds of contributions to science. In addition to contributions at the level of experiment and theory, we need to include contributions which articulate, explore and criticise possible aims for science. Scientific journals, textbooks, and educational courses need to include a discussion of all three kinds of contributions. It ought to be possible to win a Nobel prize by a sufficiently brilliant contribution at any of these three levels. We need to regard our scientific knowledge as consisting not only of what we know, but also of our best conjectures about what we do not know, but hope and desire to discover. We are never completely ignorant of that which we do not know; for if we were, we could have no basis for our assumption that the domain of our ignorance will not suddenly intrude upon the domain of our knowledge in some violent, unruly fashion, entirely disrupting the straightforward predictions of our present day scientific theories. Without some vague knowledge of that of which we are ignorant, all scientific knowledge would be impossible.

All this was well known to Einstein (Ideas and Opinions, Souvenir Press, 1973). He understood clearly that theoretical physics is only a worthwhile, rational entenprise when pursued as an attempt to discover a conjectured unified harmony in nature, the basic aims of physics thus being permanently and profoundly problematic. The success of Einstein's contribution to physics arose in large measure from his ceaseless concern to articulate and develop the best possible aims for physics, taking into account both existing knowledge and our desire to discover unity and harmony, appropriate heuristic rules then being formulated as guidelines to the development of new theories. I suggest that this kind of aim-oriented empinicist methodology, exploited with such success by Einstein within the restricted field of theoretical physics, is of universal relevance to science and technology.

At present aim articulation, as envisaged here, does not proceed as an integral part of scientific enquiry, just because most scientists take standard empiricism for granted. Once standard empiricism is accepted, scientific rigour and rationality actually seem to require that articulation and discussion of possible and actual aims for science be excluded from the intellectual domain of science. Thus, as a result of the attempt to make science conform to the intellectual ideals of standard empiricism, soientists have served to undermine the rigour and rationality of science, precisely because the vital task of anticulating and exploring possible aims for science has been somewhat inhibited and repressed. As I have argued in greater detail elsewhere (Phil. Sci., 41, 123-53, 247-95 (1974); What's Wrong with Science?, Bran's Head Books, London, 1976), there is at present an urgent need for the scientific community to free science from the irrational ideals of standard empiricism, and to put into practice the kind of aim-oriented empiricist conception of science so successfully practised by Einstein. 